\title{
UMA BREVE ANÁLISE SOBRE A GESTÃO FINANCEIRA DO MUNICÍPIO DE VITÓRIA DA CONQUISTA-BA NO PERÍODO DE VINTE ANOS DE ADMINISTRAÇÃO DO PARTIDO DOS TRABALHADORES.
}

\author{
A brief analysis on the financial management of the municipality of Vitória da Conquista - BA in the \\ period of twenty years of administration of the Party of the Workers.
}

Una breve análisis sobre la gestión financiera del municipio de Vitória da Conquista - BA en el período de venecia años de administración del Partido de los Trabajadores.

João Gabriel Cruz Nascimento ${ }^{1}$ Luiza Ferraz Telles França ${ }^{2}$

\footnotetext{
${ }^{1}$ Pós-Graduado em Gestão Pública Municipal pela Universidade Estadual do Sudoete da Bahia - UESB, email joaogabrielcn@gmail.com ${ }^{2}$ Professora do colegiado de Ciências Contábeis da Fainor, mestre em Contabilidade pela FUCAPE, Pós-Graduada em Gestão Pública Municipal pela Universidade Estadual do Sudoete da Bahia - UESB, .email luizaftf@uesb.edu.br
}

\section{Resumo}

Este trabalho objetuviu avaliar a gestão dos recursos financeiros arrecadados no período de 20 anos da administração do PT na Prefeitura Municipal de Vitória da Conquista, utilizando como parâmetro o modelo de gestão municipal desenvolvido pelo Centro de Estudos em Administração Pública da Fundação Getúlio Vargas. A base teórica do trabalho está firmada na administração do desenvolvimento, no desenvolvimento local e nas políticas públicas, além da caracterização do município objeto do estudo. Para a realização da pesquisa foi utilizada uma abordagem quantitativa, sendo feita uma análise dos dados através de estatística descritiva. Os resultados encontrados demonstram a evolução da gestão financeira de Vitória da Conquista e são utilizados como fundamento para apresentar qual o caminho a ser seguido pela Gestão Pública.

Palavras-chave: Admnistração pública; Gestão financeira; Partido dos Trabalhadores.

\begin{abstract}
This study aimed to evaluate the management of financial resources collected during the 20 years of the PT administration in the Municipality of Vitória da Conquista, using as a parameter the municipal management model developed by the Center for Studies in Public Administration of the Getúlio Vargas Foundation. The theoretical basis of the work is based on development management, local development and public policies, as well as the characterization of the municipality being studied. A quantitative approach was used to carry out the research, and a data analysis was performed through descriptive statistics. The results obtained demonstrate the evolution of the financial management of Vitória da Conquista and are used as a basis to present the way forward to be followed by Management Public.
\end{abstract}

Keywords: Public administration; Financial management; Workers' Party.

\section{Resumen}

Este trabajo objetuvió evaluar la gestión de los recursos financieros recaudados en el período de 20 años de la administración del PT en el Ayuntamiento Municipal de Vitória da Conquista, utilizando como parámetro el modelo de gestión municipal desarrollado por el Centro de Estudios en Administración Pública de la 
Fundación Getúlio Vargas. La base teórica del trabajo está firmada en la administración del desarrollo, en el desarrollo local y en las políticas públicas, además de la caracterización del municipio objeto del estudio. Para la realización de la investigación se utilizó un abordaje cuantitativo, siendo realizado un análisis de los datos a través de estadística descriptiva. Los resultados encontrados demuestran la evolución de la gestión financiera de Vitória da Conquista y se utilizan como fundamento para presentar cuál es el camino a seguir por la Gestión Público.

Palabras clave: Administracion publica; Gestión financiera; Partido de los Trabajadores.

\section{Introdução}

A Administração do Desenvolvimento é o campo que estuda as relações sociais de produção, distribuição e consumo da sociedade, surgiram para promover o desenvolvimento dos países, sociedades, nações, regiões. Segundo Motta (1972) a administração do desenvolvimento tornou-se uma grande preocupação dos estudiosos da administração pública em função de uma grande lacuna existente entre a elaboração de planos de desenvolvimento econômicos e a capacidade administrativa dos governos em implementá-los. Tantos teóricos, quanto técnicos que atuam na área de administração pública, buscam hoje, modelos de desenvolvimento que sejam adequados ás necessidades e à realidade de cada localidade.

As decisões administrativas por políticas públicas, em detrimento de outras, são determinantes no estabelecimento dos planos de desenvolvimento das entidades públicas, sejam elas das esferas nacional, estadual ou municipal. As políticas públicas tomam forma através dos programas públicos, projetos, leis rotinas administrativa, dentre outros. A operacionalização dessas políticas públicas se dá em diversas áreas tais como: saúde, educação, segurança, gestão. Sendo esta última o objeto desta pesquisa, através da avaliação dos recursos financeiros geridos pela administração municipal.

A cidade de Vitória da Conquista durante vinte anos esteve sob o comando de gestores vinculados ao Partido dos Trabalhadores, desde 1997, da seguinte forma: 19972000- Governo Guilherme Menezes; 2001-2004 - Governo Guilherme Menezes/José Raimundo Fontes; 2005-2008 - Governo José Raimundo Fontes; 2009-2012 - Governo Guilherme Menezes; 2013-2016 - Governo Guilherme Menezes. O lapso temporal de vinte anos no poder permite aos envolvimentos um profundo conhecimento das necessidades da cidade, sendo assim, será analisado durante o trabalho, quais os erros e acertos do Partido dos Trabalhadores no comando da cidade.

A questão que se busca responder com esse trabalho é: a gestão dos recursos financeiros, no período de 1997 a 2016, durante a administração do Partido dos 
Trabalhadores - PT à frente da Prefeitura Municipal de Vitória da Conquista atende ao que é preconizado no modelo proposto na cartilha Desenvolvimento Local com equidade em municípios de pequeno porte - Como Utilizar a plataforma básica, da Fundação Getúlio Vargas - FGV? O objetivo desse trabalho é avaliar a gestão dos recursos financeiros arrecadados no período de 20 anos da administração do PT na Prefeitura Municipal de Vitória da Conquista.

Para alcançar o objetivo traçado será utilizado como parâmetro o modelo proposto na cartilha Desenvolvimento Local com equidade em municípios de pequeno porte - Como Utilizar a plataforma básica, desenvolvida no ano de 2010, pelo Centro de Estudos em Administração Pública e Governo da Escola de Administração de Empresas de São Paulo da Fundação Getúlio Vargas. Para a realização da pesquisa foi utilizada uma abordagem quantitativa, sendo feita uma análise dos dados através de estatística descritiva. Para uma melhor compreensão do desempenho dos indicadores em questão foi utilizada a técnica de variação percentual.

A escolha pela aplicação da pesquisa no município de Vitória da Conquista se dá em função do mesmo ser o centro de uma região formada por 24 municípios, sendo que o seu PIB - Produto Interno Bruto do município, no ano de 2010, representava 67,63\% de todo PIB do Território de Identidade do Sudoeste, segundo dados as SEI Superintendência de Estudos Econômicos e Sociais da Bahia. Além disso, a possibilidade de se analisar a escolha por determinada política pública por um período de 20 anos, com a manutenção de um mesmo projeto político no poder de um município, representa um ganho para este trabalho.

\section{Políticas públicas como instrumento para o desenvolvimento}

O crescimento vertiginoso das cidades conduz o surgimento de problemas que são típicos do desenvolvimento municipal e trazem como consequências diversos desafios para a gestão pública, como por exemplo, produção e destinação do lixo, saneamento básico, poluição, oferta de emprego, transporte público, mobilidade urbana.

Considerando as diversas dificuldades enfrentadas pelos Prefeitos, é possível citar alguns problemas que diretamente interferem na forma de como o serviço público será executado, são problemas como à falta de apoio por parte de outras esferas de governo, estadual e federal, a insuficiência de recursos financeiros, e estrutura física precária, a falta de recursos humanos. 
Mesmo com todos os problemas existentes dentro da estrutura do município, a gestão municipal possui ferramentas que podem ser utilizadas para reduzir as adversidades e promover para a sociedade um ambiente de bem-estar.

Dentre tais ferramentas, é possível apontar as políticas públicas como um caminho a ser adotado pelo gestor público para dirimir as desigualdades, seja promovendo o esporte para jovens ou incentivando a participação popular através da criação de associação de moradores para identificar quais as carências de cada bairro, os caminhos que o município pode adotar para modificar sua realidade reforçam a autonomia administrativa que foi conferida pela Constituição Federal de 1988 para atender o interesse local.

Para definir política pública, Leonardo Secchi na obra Políticas Públicas Conceitos, Esquemas de Análise, Casos Práticos, com maestria, explica que mesmo com a difícil tarefa de definir política pública, é possível afirmar que são dois os elementos que compõe uma política pública: a intenção pública e resposta para um problema público. Ou seja, a razão para estabelecer uma política pública e buscar resolver um problema.

Explica o autor que promover políticas públicas pode ser tarefa do Estado ou de outras instituições como organizações privadas, organizações não governamentais. A abordagem estatistaconsidera tal tarefa como monopólio de entes estatais e possui fundamento na hierarquia e exclusividade que o Estado possui para instituir leis e fazer com que a sociedade cumpra com a legislação. Já a abordagem multicêntrica, considera que outros agentes como ONG's e instituições privadas, podem criar políticas para enfrentar problemas sociais, neste sentido, a abordagem multicêntrica vincula o adjetivo "pública" a uma política quando o problema que será combatido é público.

Sobre a criação de políticas públicas, e as divergências existentes entre a abordagem estatista e multicêntrica, explica o autor:

"A abordagem estatista admite que autores estatais até tenham influência no processo de elaboração e implementação de políticas públicas, mas não confere a eles o privilégio de estabelecer (decidir) e liderar um processo de política pública. Já os acadêmicos da vertente multicêntrica admitem tal privilégio a atores não estatais. Por exemplo, uma organização não governamental de proteção à natureza que lança uma campanha nacional para o replantio de árvores nativas. Esta é uma orientação à ação, e tem o intuito de enfrentar um problema de relevância coletiva. No entanto, é uma orientação dada por um ator não estatal. Aqueles que se filiam à abordagem estatista não a consideram uma política pública, porque o ator protagonista não é estatal. Por outro lado, autores da abordagem 
multicêntrica a consideram política pública, pois o problema que se tem em mão é público". (SECCHI, 2013, p. 15).

Sendo assim, compreendendo a importância do ente estatal para promover o bem-estar social, é possível afirmar que, sob uma ótica analítica, o Estado não pode ser considerado o único ente capaz de produzir políticas públicas para assegurar a supremacia do interesse público, a orientação estatista pode ser aceita sob o ponto de vista normativo, ou seja, o Estado como o único detentor do poder, mas tal orientação aumenta o monopólio do Estado e conforme tem-se verificado, é flagrante que a administração pública apresenta deficiências para manter o perfeito funcionamento dos serviços públicos.

Importante apontar que o Estado se destaca em relação a outros atores no que se refere a criação de políticas públicas. Essa relevância surge por conta da característica do estado moderno em elaborar políticas públicas, seja porque o Estado detém o monopólio, ou porque o Estado controla grande parte dos recursos nacionais.

Outro questionamento que faz parte da definição de políticas públicas segundo o autor Leonardo Secchi é considerar, ou não, que políticas públicas também se referem à omissão ou à negligência, ou seja, política pública diz respeito a tudo que os governos fazem ou não fazem.

O autor esclarece que a omissão e/ou a negligência não devem constituir as políticas públicas:

\footnotetext{
"A partir da concepção de política como diretriz é bastante difícil aceitar a omissão como forma de política pública. A lógica desse argumento é: se um problema público é interpretativo, e todos os cidadãos visualizam problemas públicos de forma diferenciada, todo e qualquer problema, por mais absurdo que seja, daria luz a uma política pública, Se todas as omissões ou negligências de atores governamentais e não governamentais fossem consideradas políticas públicas, tudo seria política pública. Ademais, seria impossível visualizar a implementação da política pública, bem como será impossível distinguir entre impactos da política pública e o curso natural das coisas" (SECCHI, 2013, p.18).
}

Tal orientação, que a omissão e a negligência do ente estatal não deve ser considerada como política pública, se mostra coerente pelo simples motivo: a atual atuação do Estado já mostra-se como deficiente e reconhecer a omissão estatal como política é um descaso com o social, o ente estatal deve assumir uma postura ativa e promover políticas públicas que possam refletir melhorias na sociedade.

No que se refere aos tipos de políticas públicas, Secchi (2013) fala em diversos tipos, políticas que indicam maior ou menor intervenção estatal. $\mathrm{O}$ referido autor apresenta inicialmente uma divisão das políticas públicas, conforme o modelo proposto por Theodore J, Lowi, com base no critério de "impacto esperado na sociedade", 
estabelecendo que existem as políticas regulatórias, que estabelecem padrões de comportamento, serviço ou produto para os atores públicos e privados, sendo como exemplos deste tipo de política as regras de segurança alimentar, leis e códigos de ética em assuntos como eutanásia e aborto, proibição de fumo em locais fechados.

Há também as políticas distributivas que geram benefícios para alguns grupos de atores e custos difusos para toda a sociedade/contribuinte, como exemplo deste tipo de política são os subsídios, gratuidade de taxas para usuários de serviços públicos, incentivos ou renúncias fiscais.

Neste sentido, imperioso apontar que a cidade de Vitória da Conquista/BA, como característica comum em cidades do seu porte, também possui na indústria uma das fontes de renda do município, o Distrito Industrial dos Imbóres, localizado a $5 \mathrm{~km}$ ao norte do centro da cidade, na BR 116, conta com mais de trinta indústrias nos diversos ramos e deve merecer maior atenção do Gestor Público. Utilizar de políticas que visam incentivos fiscais pode ser um caminho a ser adotado para promover o crescimento do número de trabalhadores do município e consequentemente a renda per capita.

Existem também as políticas do tipo redistributivas que concedem benefícios concentrados a algumas categorias de atores e implicam custos concentrados para outras categorias de atores, como exemplo, cotas raciais para universidades e os programas de reforma agrária. Mister destacar que nos filiamos a posição que as políticas de cotas raciais são benéficas, por algum tempo, para a sociedade tendo em vista que qualquer política que ofereça um caminho para a educação é válida, independente do grupo que será favorecido, seja para pessoas de baixa renda, negros, quilombolas, promover o acesso em universidades particulares através do ENEM, FIES etc.

Logo, percebe-se que alguns tipos de políticas públicas que são voltadas para atender um determinado setor da sociedade geram um conflito entre os atores, entretanto, deve-se compreender que algumas políticas reafirmam direitos sociais como educação e saúde, este procedimento, qual seja, conceder melhorias para certo grupo social, não deve ser entendido como uma benesse para determinado setor da sociedade em detrimento de outro, algumas políticas públicas podem apresentar um caráter restritivo, mas na verdade possuem como pano de fundo a melhoria para a coletividade.

Conforme a Constituição da República de 1988, a República Federativa do Brasil é constituída pela união indissolúvel dos Estados, Municípios e do Distrito Federal (CF88, Art. $1^{\circ}$ ), sendo responsabilidade de todos os componentes buscar o 
perfeito funcionamento da Federação. A Carta Magna traz ainda a repartição das competências, definindo que o Município possui competência residual e complementar, autorizado para legislar em questões de interesse local.

Sobre a competência tributária, compete aos Municípios instituir Imposto sobre a Propriedade Predial e Territorial Urbana (IPTU), tributo que possui origem desde a época do Império, tem como fato gerador a propriedade, o domínio útil ou a posse de bem imóvel, localizado na zona urbana do município. Tal imposto possui como característica a progressividade extrafiscal, prevista na $\mathrm{CF} / 88$, no art. $182, \S^{\circ}$, faculta ao Poder Público Municipal, mediante lei específica para aérea incluída no plano diretor, exigir do proprietário de solo urbano não edificado, subutilizado ou não utilizado, alíquota diferenciada.

Considerando os valores que a cidade de Vitória da Conquista-BA arrecadou através do IPTU e entre outros tributos que compõe a receita, pode-se afirmar que o Gestor Público deve utilizar parte desta verba e aplicar em diversas políticas para atender toda a sociedade, assim como parte do PIB do Brasil possui destinação para educação, o mesmo deve ser utilizado com as políticas públicas no âmbito municipal, o amplo alcance da matéria pode abranger as diversas necessidades da sociedade, desde a educação em projetos de alfabetização, incentivo à leitura, concurso literários, até a promoção de eventos esportivos para identificar jovens que possuem potencial para o esporte.

Da mesma forma o Poder Executivo e Legislativo Municipal deve utilizar compreender que alguns problemas locais podem ser resolvidos com a participação da sociedade, buscar identificar os problemas locais e utilizar parte do valor que o Município arrecada é o caminho a ser adotado para buscar fornecer para os diversos setores da sociedade melhorias e qualidade de vida, é possível ainda utilizar de sistema de rodízio para atender as diversas áreas no decorrer do ano.

Importante destacar que ao promover o desenvolvimento local do Município de Vitória da Conquista-BA, outras localidades serão beneficiadas considerando que a cidade supramencionada é capital de outras localidades. Ou seja, o ambiente que a cidade está inserida pode favorecer o crescimento dos outros municípios, ao buscar utilizar das políticas públicas para o desenvolvimento local, consequentemente irá ocorrer o desenvolvimento regional, claro que essa relação do desenvolvimento local e regional deve ser incentivada e reafirmada, seja através da participação da sociedade, do 
setor empresarial e, principalmente, do Poder Público, considerando que este possui as ferramentas necessárias para promover o bem estar social.

\section{Aspectos socioespaciais de Vitória da Conquista, enquanto cidade média.}

O Município de Vitória da Conquista, de acordo com dados divulgados, em 2016, pelo IBGE - Instituto Brasileiro de Geografia e Estatística apresenta população estimada em 346.069 habitantes, ocupando a posição de terceira maior cidade da Bahia, e sendo a capital regional de uma microrregião que abrange aproximadamente vinte e quatro municípios e possui população estimada em 676.323 habitantes.

Santos (2010) define como cidade média aquela que é centro regional de uma rede urbana. Considerando aspectos tais como padrão demográfico, raio de ação do município, a especialização em determinados serviços ou áreas produtivas. Na Bahia, afirma o autor, o padrão demográfico para o estabelecimento das cidades médias está colocado entre 50.000 e 500.000 habitantes. Vitória da Conquista está incluída nesta classificação ainda que consideremos somente o critério demográfico.

Para Santos (2012) existem três tipos de cidades médias: (i) como centro de triagem e consumo de renda fundiária, (ii) como centro de atividades especializadas e (iii) como lugar central, que se caracteriza por ofertar bens e serviços para uma rede de municípios regional e é comumente chamada de "capital regional". O autor destaca que essa caracterização tem um foco principalmente no comércio varejista e na prestação de serviços variados. Ferraz (2009) apresenta o quadro do crescimento de Vitória da Conquista que até meados da década de 1950 tinha uma população predominantemente rural, mas que a partir das modificações técnicas, das transformações nas relações sociais e a outras variáveis, observou um aumento populacional e uma transformação do seu espaço urbano modificando as redes estabelecidas até então. Vários movimentos ocorreram desde o século XVII até os nossos dias para que a cidade se tornasse a “capital regional” que é hoje, como afirma Alves (2014) é inegável o papel de Vitória da Conquista como cidade média junto a seu território de influência, além de ser uma realidade a condição de disseminadora de melhor qualidade de vida para os habitantes de toda a região.

O Território de Identidade de Vitória da Conquista (Sudoeste Baiano) é composto administrativamente pelos municípios de Anagé, Aracatu, Barra do Choça, Belo Campo, Bom Jesus da Serra, Caetanos, Cândido Sales, Caraíbas, Condeúba, 
Cordeiros, Encruzilhada, Guajeru, Jacaraci, Licínio de Almeida, Maetinga, Mirante, Mortugaba, Piripá, Planalto, Poções, Presidente Jânio Quadros, Ribeirão do Largo, Tremedal e Vitória da Conquista.

O referido território de identidade, de acordo com números da SEI Superintendência de Estudos Econômicos da Bahia, o setor de comércio e serviços tem representação de 78\% no PIB em 2010, em alguns municípios do território, a contribuição do setor terciário chega a ultrapassar 80,0\% (Caetanos, 82,0\%; Maetinga, 82,8\%; e Piripá, 82,8\%). As exceções são Ribeirão do Largo, que, devido à produção de cana-de-açúcar, banana e mandioca, tinha 33,6\% de seu PIB proveniente do setor agropecuário em 2010, e Barra do Choça, com 23,4\% do PIB derivado do setor agrícola, graças ao cultivo do café.

Em termos econômicos, os municípios do território de identidade que apresentaram os maiores indicadores do PIB foram Vitória da Conquista (R \$ 3,9 bilhões), Poções (R \$ 266 milhões), Encruzilhada (R \$ 139 milhões), Planalto (R 136 milhões) e Cândido Sales (R 124 milhões). Os menores são Maetinga (R\$ 29 milhões) e Guajeru (R\$ 31 milhões).

Alves (2014) destaca que quando observados os indicadores econômicos do município de Vitória da Conquista e sua região, é possível verificar o baixo crescimento e resultados pouco significativos do PIB no resultado geral do estado da Bahia. Afirma ainda a autora que, o resultado observado é fruto de suas características econômicas mais fortes serem o comércio e serviços, posto que os mesmos não necessitem de um alto grau de especialização, nem de competitividade.

Para além dos indicadores é possível observar a relação estabelecida entre o Município de Vitória da Conquista e os municípios que estão em seu entorno, caracterizadas como cidades de pequeno porte, sendo o papel de intermediadora que Vitória da Conquista exerce entre esses municípios de pequeno porte e os centros maiores um importante reforço do papel de cidade média de Vitória da Conquista, junto a sua região de influência (ALVES, 2014, p. 353).

Vitória da Conquista obteve, segundo informação do Programa das Nações Unidas para o Desenvolvimento - PNUD, Índice de Desenvolvimento Humano (IDHM) de 0,678, em 2010, o que situa o município na faixa de Desenvolvimento Humano Médio (IDHM entre 0,600 e 0,699), ocupando a posição $2481^{\mathrm{a}}$ entre os 5.565 municípios brasileiros. Em 1991, o IDHM de Vitória da Conquista era de 0,409, e em 2000 de 0,538. O IDHM obteve entre 1991 e 2000 uma taxa de crescimento de 31,54\%. 
O hiato de desenvolvimento humano, ou seja, a distância entre o IDHM do município e o limite máximo do índice, que é 1, foi reduzido em 78,17\% entre 1991 e 2000. E obteve entre 2000 e 2010 uma taxa de crescimento de $26,02 \%$. O hiato de desenvolvimento humano foi reduzido em 69,70\% entre 2000 e 2010. Mesmo assim, as desigualdades sócioespaciais persistem (ROCHA, 2011, p, 11)

A cidade de Vitória da Conquista durante vinte anos esteve sob o comando de gestores vinculados ao Partido dos Trabalhadores, desde 1997, da seguinte forma: 19972000- Governo Guilherme Menezes; 2001-2004 - Governo Guilherme Menezes/José Raimundo Fontes; 2005-2008 - Governo José Raimundo Fontes; 2009-2012 - Governo Guilherme Menezes; 2013-2016 - Governo Guilherme Menezes.

\section{Abordagem metodológica para análise dos aspectos da gestão municipal}

Com vistas a alcançar o objetivo proposto para este trabalho foi utilizado o modelo apresentado na cartilha Desenvolvimento Local com Equidade em Municípios de Pequeno Porte - Como Utilizar a Plataforma Básica, desenvolvida no ano de 2010, pelo Centro de Estudos em Administração Pública e Governo da Escola de Administração de Empresas de São Paulo da Fundação Getúlio Vargas. Essa Plataforma Básica é composta de informações e indicadores que têm uma atualização periódica de, no geral, um ano; o que significa que nós podemos acompanhar seu desenrolar ano a ano e, em alguns casos, mês a mês. Podemos também olhar para trás para ver como era a situação em anos anteriores. Ela está dividida em três eixos: Gestão, Desenvolvimento Econômico Local e Desenvolvimento Social e Redução das Desigualdades.

Quadro 1 - Indicadores de Gestão

\begin{tabular}{|c|c|c|}
\hline EIXO & GRUPO & INDICADOR \\
\hline \multirow{4}{*}{ 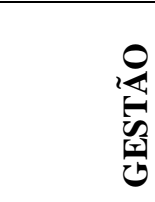 } & Receitas próprias & IPVA, IPTU, ISS, ICMS, IRPF, outros. \\
\hline & Transferências & $\begin{array}{l}\text { FPM, FUNDEB, FNS/SUS, apoio à } \\
\text { alimentação escolar }\end{array}$ \\
\hline & Convênios & Convênios municipais \\
\hline & Gasto Municipal & Categoria econômica, função \\
\hline
\end{tabular}

Fonte: Elaborado pelos autores a partir do Modelo de quadro de indicadores de desenvolvimento local com equidade em municípios de pequeno porte - Como utilizar a plataforma básica. Centro de Estudos em Administração Pública e Governo da Escola de Administração de Empresas de São Paulo da FGV (2010).

Como estratégia de pesquisa o foco será o eixo da Gestão. Buscando informações acerca dos recursos que o município tem à sua disposição, ou seja, recursos 
de "gestão", aqueles que a administração municipal tem ao seu dispor para gerar resultados, conforme apresentado na tabela 1, bem como uma análise dos gastos municipais no período estudado. Para a realização da pesquisa foi utilizada uma abordagem quantitativa, sendo feita uma análise dos dados através de estatística descritiva. Para uma melhor compreensão do desempenho dos indicadores em questão foi utilizada a técnica de variação percentual.

A coleta dos dados foi efetuada no sitio da Secretaria do Tesouro Nacional, através da consulta ao SINCONFI - Sistema de Informações Contábeis e Fiscais do Setor Público Brasileiro. O referido sistema apresenta os balanços anuais dos municípios brasileiros a partir do ano de 2000, portanto, para este trabalho foram utilizadas informações sobre receitas e gastos públicos do ano 2000 até 2016. Quanto ao número de convênios celebrados, foram coletados dados no sitio de transparência da Prefeitura Municipal de Vitória da Conquista.

\section{Avaliação e análise dos dados da gestão}

O primeiro ponto avaliado dentro do eixo da gestão é o que compreende os indicadores de arrecadação de impostos e taxas, dentre outros e que neste trabalho foi classificado como receitas próprias. Os valores apresentados na tabela 1 foram apurados a partir dos balanços orçamentários da PMVC e incluem os valores de receitas correntes e receitas de capital arrecadadas.

Tabela 1 - Receitas próprias arrecadadas pela Prefeitura Municipal de Vitória da Conquista

\begin{tabular}{c|c|c}
\hline Ano & Total das Receitas Próprias & Crescimento \\
\hline 2000 & $\mathrm{R} \$ 12.784 .591,00$ & - \\
\hline 2001 & $\mathrm{R} \$ 13.048 .744,00$ & $2,07 \%$ \\
\hline 2002 & $\mathrm{R} \$ 48.464 .877,57$ & $271,41 \%$ \\
\hline 2003 & $\mathrm{R} \$ 21.767 .891,73$ & $-55,09 \%$ \\
\hline 2004 & $\mathrm{R} \$ 24.194 .042,00$ & $11,15 \%$ \\
\hline 2005 & $\mathrm{R} \$ 39.874 .313,35$ & $64,81 \%$ \\
\hline 2006 & $\mathrm{R} \$ 32.920 .912,00$ & $-17,44 \%$ \\
\hline 2007 & $\mathrm{R} \$ 41.205 .597,00$ & $25,17 \%$ \\
\hline 2008 & $\mathrm{R} \$ 46.839 .070,81$ & $13,67 \%$ \\
\hline 2009 & $\mathrm{R} \$ 48.473 .962,51$ & $3,49 \%$ \\
\hline 2010 & $\mathrm{R} \$ 60.403 .931,08$ & $24,61 \%$ \\
\hline 2011 & $\mathrm{R} \$ 75.910 .428,77$ & $25,67 \%$ \\
\hline 2012 & $\mathrm{R} \$ 88.933 .744,53$ & $17,16 \%$ \\
\hline 2013 & $\mathrm{R} \$ 105.220 .020,05$ & $18,31 \%$ \\
\hline 2014 & $\mathrm{R} \$ 121.830 .058,84$ & $15,79 \%$ \\
\hline 2015 & $\mathrm{R} \$ 124.076 .895,44$ & $1,84 \%$ \\
\hline
\end{tabular}


Fonte: Elaborado pelos autores a partir dos dados do SICONFI.

As receitas próprias arrecadadas no período estudado apresentam um crescimento geral do período de 1.057,69\%. Esse crescimento é significativo quando comparado, por exemplo, com o IPCA - Índice de Preços ao Consumidor Ampliado, que é produzido pelo Instituto Brasileiro de Geografia e Estatística (IBGE) desde 1979, sendo considerado o indicador oficial do Governo Federal para aferição das metas inflacionárias, e que no mesmo período foi de $199,74 \%$. Existe no período estudado, variação inconstante das recitas, com aumentos e diminuições que indicam uma política de arrecadação pouco planejada, pois apesar do crescimento acumulado apresentado, o mesmo não se deu de forma organizada e crescente.

Tabela 2 - Transferências recebidas pela Prefeitura Municipal de Vitória da Conquista

\begin{tabular}{|c|c|c|c|c|}
\hline Ano & Total das & erências & $\begin{array}{l}\text { Relação com o total das } \\
\text { receitas arrecadadas }\end{array}$ & Crescimento \\
\hline 2000 & $\mathrm{R} \$$ & $68.183 .333,00$ & $84,21 \%$ & - \\
\hline 2001 & $\mathrm{R} \$$ & 79.966.361,00 & $85,97 \%$ & $17,28 \%$ \\
\hline 2002 & $\mathrm{R} \$$ & $55.423 .003,62$ & $53,35 \%$ & $-30,69 \%$ \\
\hline 2003 & $\mathrm{R} \$$ & $95.960 .896,81$ & $81,51 \%$ & $73,14 \%$ \\
\hline 2004 & $\mathrm{R} \$$ & $140.376 .308,00$ & $85,30 \%$ & $46,28 \%$ \\
\hline 2005 & $\mathrm{R} \$$ & $164.659 .215,59$ & $80,50 \%$ & $17,30 \%$ \\
\hline 2006 & $\mathrm{R} \$$ & $163.093 .452,00$ & $83,20 \%$ & $-0,95 \%$ \\
\hline 2007 & $\mathrm{R} \$$ & $193.558 .725,00$ & $82,45 \%$ & $18,68 \%$ \\
\hline 2008 & $\mathrm{R} \$$ & $244.254 .360,42$ & $83,91 \%$ & $26,19 \%$ \\
\hline 2009 & $\mathrm{R} \$$ & $242.202 .481,35$ & $83,32 \%$ & $-0,84 \%$ \\
\hline 2010 & $\mathrm{R} \$$ & $277.544 .985,60$ & $82,13 \%$ & $14,59 \%$ \\
\hline 2011 & $\mathrm{R} \$$ & $328.750 .061,44$ & $81,24 \%$ & $18,45 \%$ \\
\hline 2012 & $\mathrm{R} \$$ & $366.620 .296,00$ & $80,48 \%$ & $11,52 \%$ \\
\hline 2013 & $\mathrm{R} \$$ & $393.097 .259,73$ & $78,88 \%$ & $7,22 \%$ \\
\hline 2014 & $\mathrm{R} \$$ & $418.402 .301,35$ & $77,45 \%$ & $6,44 \%$ \\
\hline 2015 & $\mathrm{R} \$$ & $464.586 .953,54$ & $78,92 \%$ & $11,04 \%$ \\
\hline 2016 & $\mathrm{R} \$$ & $507.147 .660,64$ & $78,95 \%$ & $9,16 \%$ \\
\hline
\end{tabular}

Fonte: Elaborado pelos autores a partir dos dados do SICONFI.

A tabela 2 apresenta os dados referentes ao recebimento de Transferências Federais e Estaduais no período analisado. Analisando a relação das transferências com o total das receitas arrecadadas pelo munícipio conclui-se que existe uma forte dependência financeira da administração local dos recursos transferidos das demais esferas de governo, posto que nos anos estudados, os valores referentes a transferências estão em torno de $80 \%$ da receita total disponível. Houve no período um aumento acumulado de Transferências recebidas de 743,80\%. 
Outro aspecto verificado no modelo proposto dela FGV é o número de convênios celebrados entre a administração municipal e os governos estadual e federal, conforme apresentado na tabela 3 .

Pode-se observar que a partir do chamado "alinhamento político", ou seja, quando o governo nas demais esferas é exercido pelo mesmo partido político, ou partidos da mesma base, o que ocorreu com Vitória da Conquista a partir do ano 2002 quando o Partido dos Trabalhadores assumiu o governo federal e mais fortemente a partir de 2007, quando o mesmo partido assumiu o governo do estado da Bahia, foi marcante para a ampliação do número de convênios firmados entre os entes públicos analisados. Quase a totalidade dos convênios celebrados foi com órgãos da União, sendo que esses representam $93,62 \%$ do volume total.

Tabela 3 - Convênios firmados pela Prefeitura Municipal de Vitória da Conquista

\begin{tabular}{|c|c|c|c|}
\hline Ano & Esfera Estadual & Esfera Federal & Total \\
\hline 1997 & 0 & 2 & 2 \\
\hline 1998 & 0 & 1 & 1 \\
\hline 1999 & 0 & 0 & 0 \\
\hline 2000 & 0 & 0 & 0 \\
\hline 2001 & 0 & 0 & 0 \\
\hline 2002 & 0 & 4 & 4 \\
\hline 2003 & 0 & 11 & 11 \\
\hline 2004 & 0 & 26 & 26 \\
\hline 2005 & 0 & 20 & 20 \\
\hline 2006 & 0 & 23 & 23 \\
\hline 2007 & 1 & 31 & 32 \\
\hline 2008 & 3 & 31 & 34 \\
\hline 2009 & 3 & 6 & 9 \\
\hline 2010 & 4 & 15 & 19 \\
\hline 2011 & 2 & 9 & 11 \\
\hline 2012 & 2 & 12 & 14 \\
\hline 2013 & 0 & 8 & 8 \\
\hline 2014 & 0 & 4 & 4 \\
\hline 2015 & 0 & 11 & 11 \\
\hline 2016 & 0 & 6 & 6 \\
\hline Total & 15 & 220 & 235 \\
\hline
\end{tabular}

Fonte: Elaborado pelos autores a partir dos dados do sitio www.portaldatransparencia.gov.br.

Pode-se observar que a partir do chamado "alinhamento político", ou seja, quando o governo nas demais esferas é exercido pelo mesmo partido político, ou partidos da mesma base, o que ocorreu com Vitória da Conquista a partir do ano 2002 quando o Partido dos Trabalhadores assumiu o governo federal e mais fortemente a partir de 2007, quando o mesmo partido assumiu o governo do estado da Bahia, foi marcante para a ampliação do número de convênios firmados entre os entes públicos analisados. Quase a totalidade dos convênios celebrados foi com órgãos da União, sendo que esses representam $93,62 \%$ do volume total. 
O último item analisado no eixo da gestão do modelo utilizado na pesquisa é o que trata dos gastos públicos. No gráfico 1 é apresentada a evolução das despesas totais pagas pela PMVC.

Figura 1 - Evolução das despesas totais pagas pela Prefeitura Municipal de Vitória da Conquista

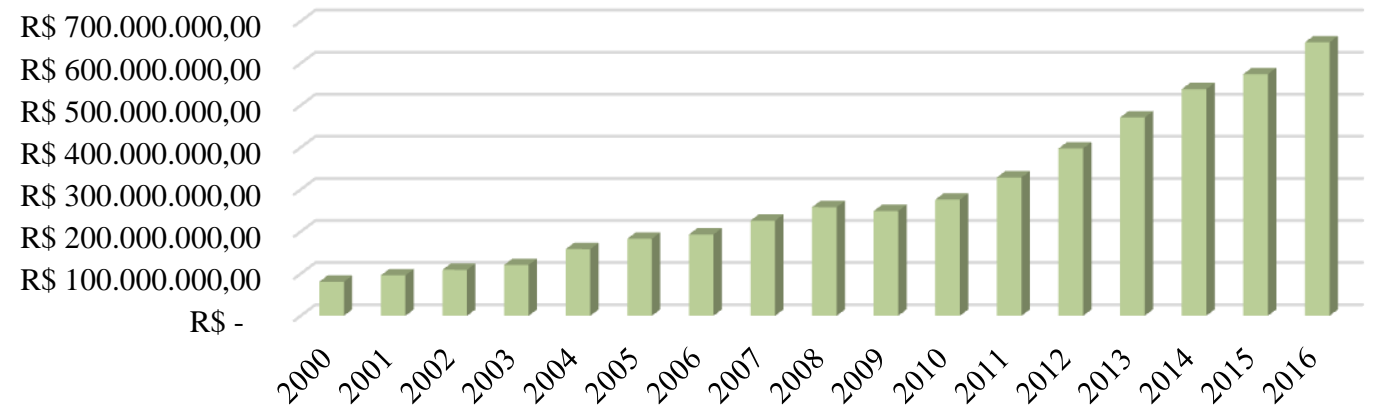

Fonte: Elaborado pelos autores a partir dos dados do SICONFI.

O crescimento das despesas totais da entidade pública estudal no período compreendido entre 2000 e 2016 foi de $804,16 \%$, o que é significativamente menor do que o crescimento das receitas arrecadadas. A tabela 4 apresenta os valores apurados de despesas pagas por período, bem como a relação das despesas com a receita arrecadada, é possível observar que, assim como ocorrido com a arrecadação das receitas não parece haver um planejamento para as despesas, visto que existem variações positivas e negativas nos anos estudados. Pode-se observar também que em alguns anos houve déficit nas contas orçamentárias da prefeitura, em função das despesas terem sido maiores que as receitas. Outra observação feita é que em todos os anos analisados o valor das despesas correntes representou cerca de $90 \%$ do total das despesas pagas pela PMVC.

Considerando as despesas por categoria econômica, elas podem ser despesas de capital ou despesas correntes. Entre as despesas de capital destacam-se os investimentos feitos pela entidade. No período analisado houve um acréscimo na ordem de 875,37\% nesse indicador de gestão. O gráfico 2 apresenta a evolução dos investimentos feitos pela Prefeitura Municipal de Vitória da Conquista nos 17 anos analisados.

Tabela 4 - Despesas pagas pela Prefeitura Municipal de Vitória da Conquista

\begin{tabular}{l|crcc}
\hline Ano & \multicolumn{2}{c}{ Total das despesas pagas } & $\begin{array}{c}\text { Relação com as receitas } \\
\text { arrecadadas }\end{array}$ & $\begin{array}{c}\text { Crescimento } \\
\text { anual }\end{array}$ \\
\hline 2000 & $\mathrm{R} \$$ & $80.731 .251,00$ & $99,71 \%$ & - \\
\hline 2001 & $\mathrm{R} \$$ & $96.040 .584,00$ & $103,25 \%$ & $18,96 \%$ \\
\hline 2002 & $\mathrm{R} \$$ & $109.214 .516,68$ & $105,13 \%$ & $13,72 \%$ \\
\hline 2003 & $\mathrm{R} \$$ & $120.710 .240,82$ & $102,53 \%$ & $10,53 \%$ \\
\hline 2004 & $\mathrm{R} \$$ & $158.349 .542,00$ & $96,22 \%$ & $31,18 \%$ \\
\hline 2005 & $\mathrm{R} \$$ & $182.943 .456,90$ & $89,44 \%$ & $15,53 \%$ \\
\hline
\end{tabular}




\begin{tabular}{c|c|c|c|c}
\hline 2006 & $\mathrm{R} \$$ & $193.223 .657,00$ & $98,58 \%$ & $5,62 \%$ \\
\hline 2007 & $\mathrm{R} \$$ & $225.987 .350,00$ & $96,26 \%$ & $16,96 \%$ \\
\hline 2008 & $\mathrm{R} \$$ & $258.042 .437,30$ & $88,65 \%$ & $14,18 \%$ \\
\hline 2009 & $\mathrm{R} \$$ & $248.970 .016,32$ & $85,65 \%$ & $-3,52 \%$ \\
\hline 2010 & $\mathrm{R} \$$ & $275.967 .644,41$ & $81,66 \%$ & $10,84 \%$ \\
\hline 2011 & $\mathrm{R} \$$ & $328.591 .651,85$ & $81,20 \%$ & $19,07 \%$ \\
\hline 2012 & $\mathrm{R} \$$ & $397.493 .490,51$ & $87,25 \%$ & $20,97 \%$ \\
\hline 2013 & $\mathrm{R} \$$ & $471.048 .091,62$ & $94,53 \%$ & $18,50 \%$ \\
\hline 2014 & $\mathrm{R} \$$ & $538.464 .498,03$ & $99,67 \%$ & $14,31 \%$ \\
\hline 2015 & $\mathrm{R} \$$ & $574.152 .411,64$ & $97,53 \%$ & $6,63 \%$ \\
\hline 2016 & $\mathrm{R} \$$ & $649.689 .174,18$ & $101,14 \%$ & $13,16 \%$ \\
\hline
\end{tabular}

Fonte: Elaborado pelos autores a partir dos dados do SICONFI.

Entre as despesas correntes, que são aquelas que se referem aos gastos constantes e recorrentes do dia a dia da entidade, e seguindo o modelo proposto pela FGV que sugere repartir os gastos por função como forma complementar de olhar o uso do dinheiro público, permitindo que se entenda com clareza como as áreas-fim de atuação governamental estão sendo contempladas dentro das disponibilidades de gasto municipal, foram selecionadas quatro áreas para efetuar a análise dos gastos públicos. São elas: administração, educação e cultura, saúde e saneamento, e urbanismo e habitação.

Figura 2 - Evolução dos Investimentos feitos pela Prefeitura Municipal de Vitória da Conquista

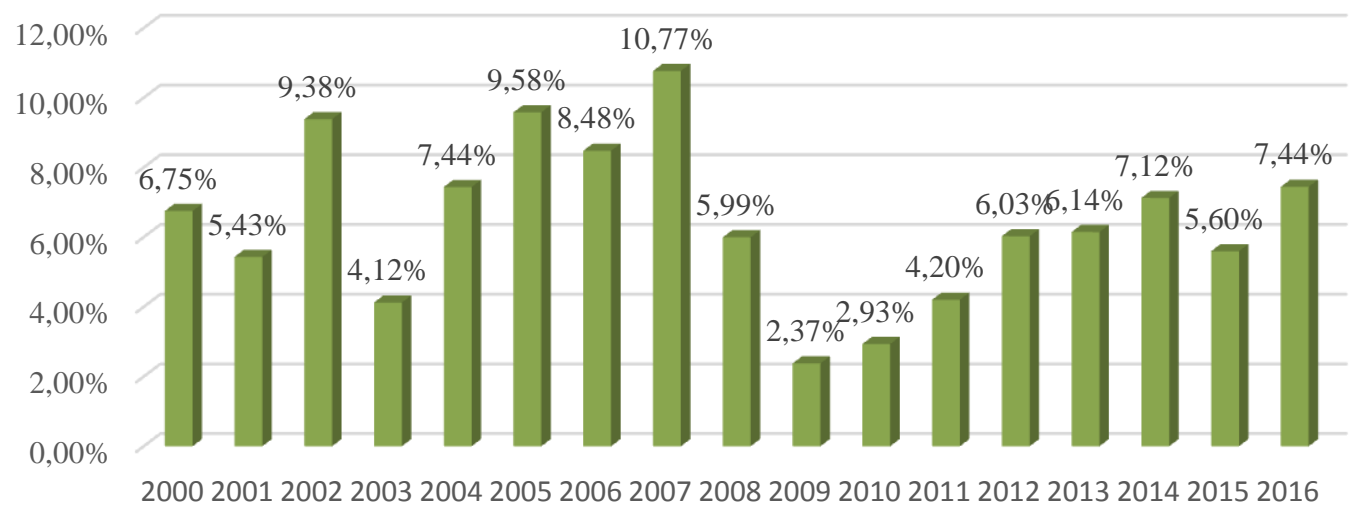

Fonte: Elaborado pelos autores a partir dos dados do SICONFI.

Os dados apresentados na tabela 5 demonstram que no período estudado as despesas pagas na função administração cresceram 204,14\%, crescimento bem inferior ao registrado pelo total das recitas arrecadadas, como também pelo total das despesas pagas. Infere-se que houve no período estudado, que compreende os governos do Partido dos Trabalhadores à frente da Prefeitura Municipal de Vitória da Conquista, houve um esforço do governo para reduzir gastos administrativos, o que pode ser verificado com relação aos gastos com educação e cultura. 
Tabela 6 - Despesas pagas pela Prefeitura Municipal de Vitória da Conquista na função administração

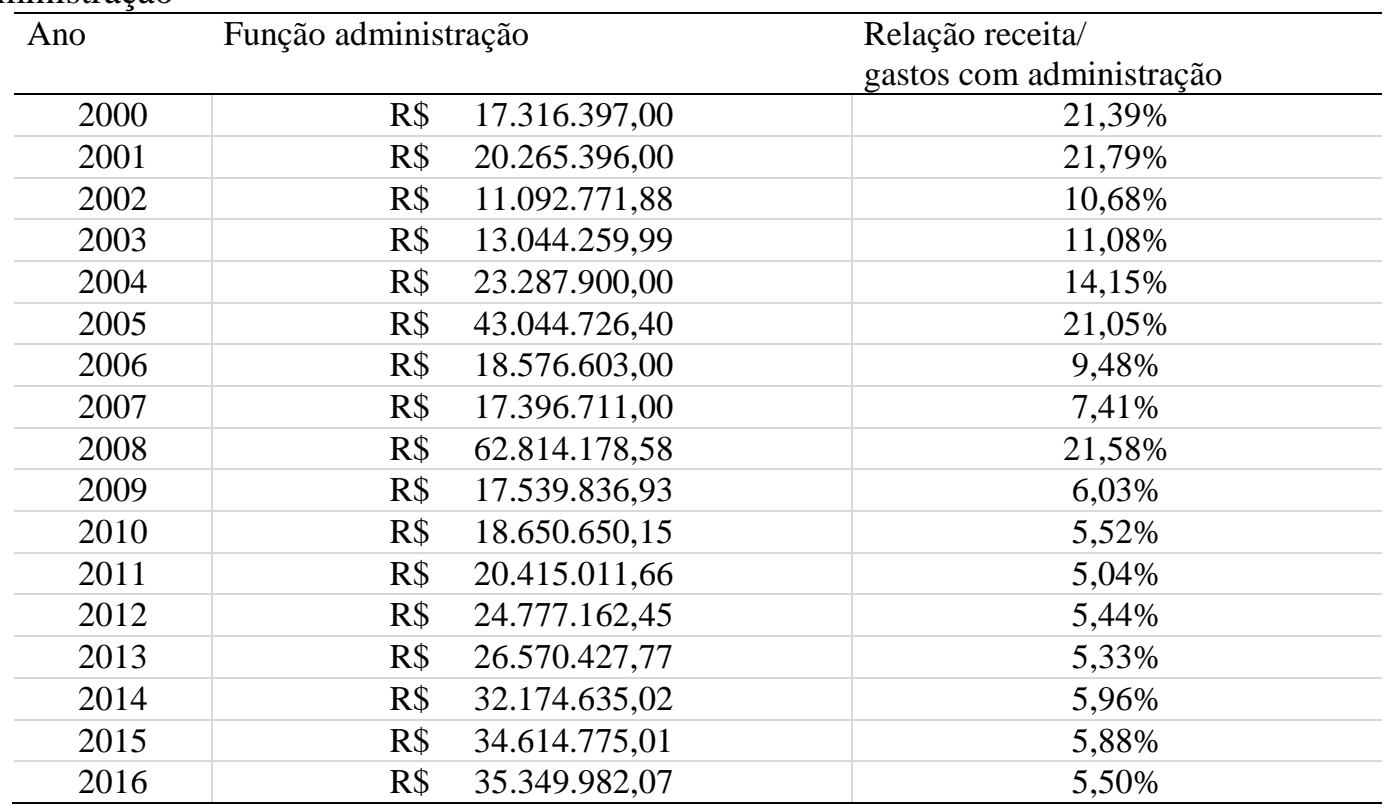

Fonte: Elaborado pelos autores a partir dos dados do SICONFI.

Os gastos públicos com a função educação e cultura cresceram 965,71\%, no período analisado. Comparando o crescimento da função educação e cultura com os gastos administrativos pode-se concluir que houve um esforço da gestão municipal em aumentar os investimentos em educação. Quando observada a relação dos gastos com educação e cultura com o total das receitas arrecadadas pelo município, destaca-se um aumento percentual desses investimentos, principalmente nos últimos 5 anos de governo, quando o índice que girava em torno dos $20 \%$, alcançou, no ano de 2016, os $30 \%$ da receita total arrecadada, conforme demonstrado na tabela 6.

Tabela 6 - Despesas pagas pela Prefeitura Municipal de Vitória da Conquista na função educação e cultura

\begin{tabular}{|c|c|c|c}
\hline Ano & & $\begin{array}{l}\text { Educação } \\
\text { e Cultura }\end{array}$ & $\begin{array}{c}\text { Relação Receita/ } \\
\text { Gatos com Educação }\end{array}$ \\
\hline 2000 & $\mathrm{R} \$$ & $19.960 .749,00$ & $24,65 \%$ \\
\hline 2001 & $\mathrm{R} \$$ & $22.570 .989,00$ & $24,27 \%$ \\
\hline 2002 & $\mathrm{R} \$$ & $26.131 .746,86$ & $25,15 \%$ \\
\hline 2003 & $\mathrm{R} \$$ & $28.186 .943,16$ & $23,94 \%$ \\
\hline 2004 & $\mathrm{R} \$$ & $31.994 .663,00$ & $19,44 \%$ \\
\hline 2005 & $\mathrm{R} \$$ & $37.218 .517,27$ & $18,20 \%$ \\
\hline 2006 & $\mathrm{R} \$$ & $41.296 .422,00$ & $21,07 \%$ \\
\hline 2007 & $\mathrm{R} \$$ & $52.804 .705,00$ & $22,49 \%$ \\
\hline 2008 & $\mathrm{R} \$$ & $57.897 .353,43$ & $19,89 \%$ \\
\hline 2009 & $\mathrm{R} \$$ & $74.938 .023,69$ & $25,78 \%$ \\
\hline 2010 & $\mathrm{R} \$$ & $85.557 .991,61$ & $25,32 \%$ \\
\hline 2011 & $\mathrm{R} \$$ & $97.978 .983,71$ & $24,21 \%$ \\
\hline 2012 & $\mathrm{R} \$$ & $129.676 .987,40$ & $28,47 \%$ \\
\hline 2013 & $\mathrm{R} \$$ & $148.774 .350,61$ & $29,86 \%$ \\
\hline 2014 & $\mathrm{R} \$$ & $160.195 .167,45$ & $29,65 \%$ \\
\hline 2015 & $\mathrm{R} \$ 175.511 .619,19$ & $29,82 \%$ \\
\hline 2016 & $\mathrm{R} \$ 192.763 .048,59$ & $30,01 \%$ \\
\hline
\end{tabular}

Fonte: Elaborado pelos autores a partir dos dados do SICONFI 
Os gastos públicos com a função saúde e saneamento, apresentados na tabela 7 , tiveram crescimento de $712,21 \%$, no período analisado. Assim como na análise dos gastos com a função educação e cultura, quando comparados aos gastos administrativos, o que ocorreu com os gastos com saúde e saneamento aponta para a ideia de que houve um esforço da gestão municipal em aumentar os investimentos nas áreas críticas da gestão municipal, quais sejam educação e saúde. No entanto quando observada a relação entre os gastos com saúde e saneamento com o total das receitas arrecadadas pelo ente público, pode-se verificar que existe uma constante no percentual das receitas investidas na função durante todo o período, tendo uma média em torno dos $30 \%$.

Tabela 7 - Despesas pagas pela Prefeitura Municipal de Vitória da Conquista na função saúde e saneamento

\begin{tabular}{|c|c|c|c|}
\hline Ano & $\begin{array}{l}\text { Saúde e } \\
\text { Saneam }\end{array}$ & & $\begin{array}{l}\text { Relação Receita/ Gatos } \\
\text { com Saúde e Saneamento }\end{array}$ \\
\hline 2000 & $\mathrm{R} \$$ & $29.371 .267,00$ & $36,28 \%$ \\
\hline 2001 & $\mathrm{R} \$$ & $39.374 .134,00$ & $42,33 \%$ \\
\hline 2002 & $\mathrm{R} \$$ & $42.474 .293,90$ & $40,88 \%$ \\
\hline 2003 & $\mathrm{R} \$$ & $47.331 .496,16$ & $40,20 \%$ \\
\hline 2004 & $\mathrm{R} \$$ & $63.259 .753,00$ & $38,44 \%$ \\
\hline 2005 & $\mathrm{R} \$$ & $53.800 .066,33$ & $26,30 \%$ \\
\hline 2006 & $\mathrm{R} \$$ & $73.733 .627,00$ & $37,62 \%$ \\
\hline 2007 & $\mathrm{R} \$$ & $86.168 .861,00$ & $36,70 \%$ \\
\hline 2008 & $\mathrm{R} \$$ & $60.081 .863,45$ & $20,64 \%$ \\
\hline 2009 & $\mathrm{R} \$$ & 106.153.109,96 & $36,52 \%$ \\
\hline 2010 & $\mathrm{R} \$$ & $115.756 .237,01$ & $34,25 \%$ \\
\hline 2011 & $\mathrm{R} \$$ & $127.289 .062,45$ & $31,46 \%$ \\
\hline 2012 & $\mathrm{R} \$$ & $140.932 .194,22$ & $30,94 \%$ \\
\hline 2013 & $\mathrm{R} \$$ & $155.971 .637,30$ & $31,30 \%$ \\
\hline 2014 & $\mathrm{R} \$$ & $179.624 .797,53$ & $33,25 \%$ \\
\hline 2015 & $\mathrm{R} \$$ & 187.137.563,98 & $31,79 \%$ \\
\hline 2016 & $\mathrm{R} \$$ & 209.186.367,53 & $32,56 \%$ \\
\hline
\end{tabular}

Fonte: Elaborado pelos autores a partir dos dados do SICONFI

A última função analisada, conforme demonstrado na tabela 8 , foi a que trata dos gastos com urbanismo e habitação. Essa função obteve no período um crescimento acumulado de 254,45\%, o que está muito próximo ao crescimento da função administração. Quando analisada a relação desses gastos com o total de receita arrecadada pela PMVC, observa-se que, com exceção do primeiro ano da série histórica, no qual foi utilizado $36,28 \%$ do total das receitas em urbanismo e habitação, nos demais períodos estudados eles ficaram em torno dos $10 \%$.

Tabela 8 - Despesas pagas pela Prefeitura Municipal de Vitória da Conquista na função urbanismo e habitação

\begin{tabular}{cccc}
\hline Ano & & $\begin{array}{l}\text { Urbanismo } \\
\text { e habitação }\end{array}$ & $\begin{array}{c}\text { Relação receita/ gastos } \\
\text { com urbanismo e habitação }\end{array}$ \\
\hline 2000 & R\$ & $29.371 .267,00$ & $36,28 \%$
\end{tabular}




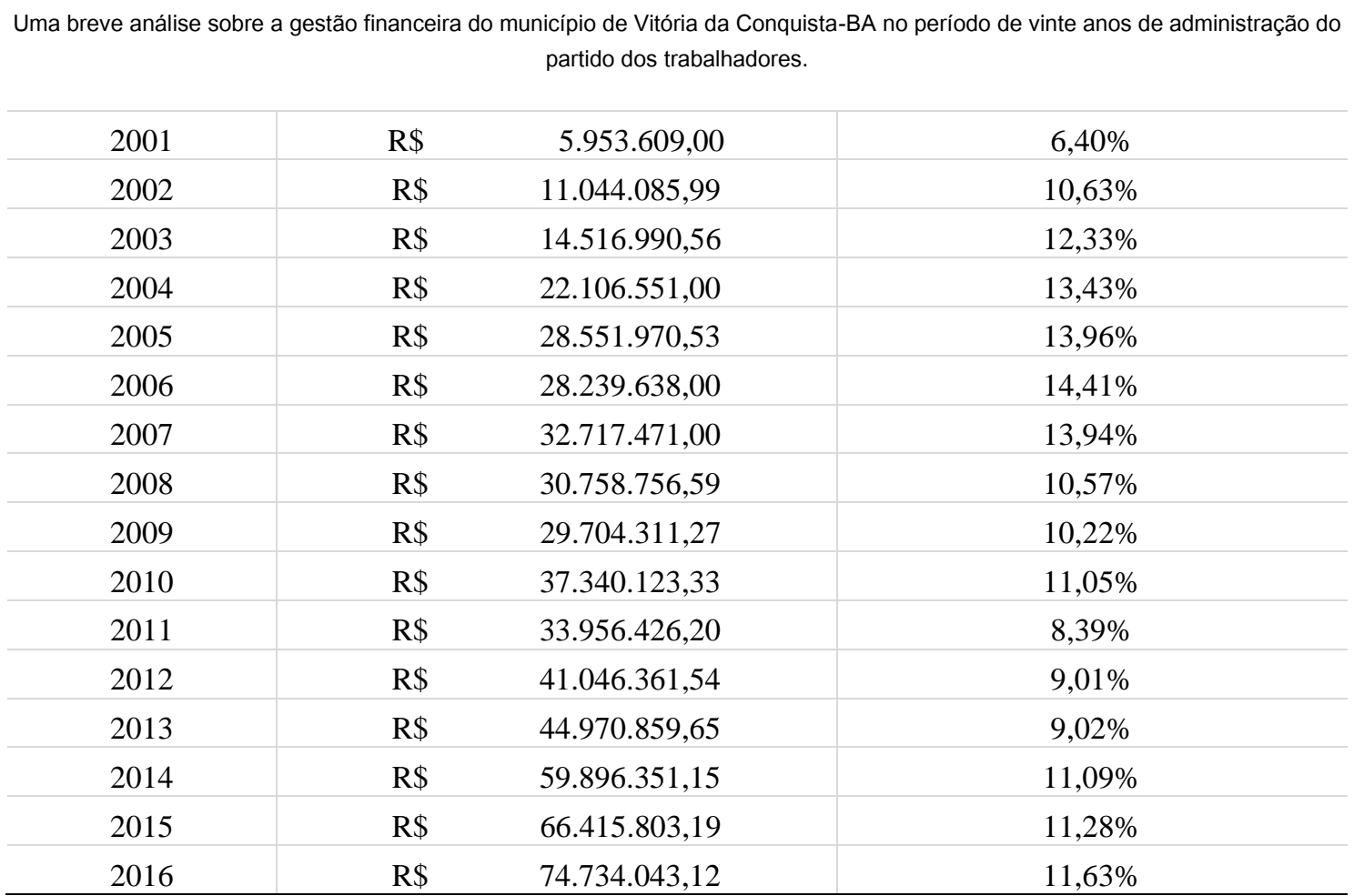

Fonte: Elaborado pelos autores a partir dos dados do SICONFI

Dentro da proposta de análise foram verificadas as receitas próprias arrecadadas, as transferências intergovernamentais recebidas, as despesas totais pagas, e dentro das categorias econômicas das despesas destacou-se os investimentos, para as despesas de capital, e os gastos com as funções de administração, educação e cultura, saúde e saneamento, e urbanismo e habitação.

\section{Considerações finais}

A presente pesquisa teve como objetivo avaliar a gestão dos recursos financeiros arrecadados no período de 20 anos da administração do Partido dos Trabalhadores na Prefeitura Municipal de Vitória da Conquista, para tanto foi utilizado o modelo apresentado na cartilha Desenvolvimento Local com Equidade em Municípios de Pequeno Porte - Como Utilizar a plataforma básica, desenvolvida no ano de 2010, pelo Centro de Estudos em Administração Pública e Governo da Escola de Administração de Empresas de São Paulo da Fundação Getúlio Vargas. Como o foco da pesquisa foi analisar a gestão financeira, utilizou-se o eixo da Gestão proposto no modelo da FGV.

$\mathrm{Na}$ análise das receitas arrecadas e transferências recebidas conclui-se que houve um aumento significativo tanto na arrecadação, quanto nas transferências, um acréscimo muito superior ao IPCA, por exemplo, que é o indicador utilizado pelo Governo Federal para balizar a inflação. Entretanto, o crescimento da arrecadação de receitas próprias não se dá de forma organizada, ou constante, indicando que houve uma falta de 
planejamento específico para essa área e que a mesma esteve sujeita a influência de fatores externos.

Com relação aos investimentos que foram feitos pela PMVC no período dos 17 anos analisados, pode-se perceber que apesar de um crescimento de $875,37 \%$ nesse indicador, quando observada a evolução anual do índice, verifica-se que na média o mesmo se manteve em cerca de $10 \%$ do total das receitas.

Quando observados os resultados encontrados na análise dos indicadores de gestão que utilizam os gastos públicos por função, a inferência que se faz é de que a gestão do Partido dos Trabalhadores à frente da Prefeitura Municipal de Vitória da Conquista, no período estudado, fez uma escolha por gastar mais com educação e saúde, sendo que o crescimento das despesas com essas duas funções foi de $800 \%$ e $700 \%$, respectivamente, enquanto os gastos com administração e urbanismos tiveram aumentos que giraram em torno dos $200 \%$. Ressalta-se que, apesar do crescimento verificado, a diferença observada na forma como os gastos variaram entre os anos estudados, nas funções educação e saúde, já que a saúde tem relação percentual com a receita arrecadada praticamente constante, enquanto o mesmo não ocorre com os gastos com educação.

Esta pesquisa possui limitações, uma vez que a pesquisa foi aplicada em período limitado de tempo e observando apenas o eixo da gestão dos recursos financeiros pela entidade. Acredita-se que em futuras pesquisas com a inclusão de outros indicadores de desempenho econômicos e sociais seja possível produzir conclusões mais apuradas.

\section{Referências}

ALVES, Rita de Cassia O. Lima. A influência de uma cidade média do sudoeste da Bahia: o caso de vitória da conquista. Tese de Doutorado, Universitat de Barcelona, 2014, 430 p.

FERRAZ, Ana Emília. O espaço em movimento: o desvelar da rede nos processos socitécnicosdo Sistema de Saúde de Vitória da Conquista - Bahia. Tese:

Doutorado.Universidade Federal de Sergipe, 2009.

FGV, Desenvolvimento Local com Equidade em Municípios de Pequeno Porte Populacional - Como utilizar a Plataforma Básica, CEAPG. São Paulo: Dedone Editora, 2010.

MOTTA, Paulo Roberto. Administração para o desenvolvimento: a disciplina em busca da relevância. Revista de Administração Pública, v. 6, n. 3, p. 39-54, 1972.

ROCHA, A. R. A produção do espaço, segregação residencial e desigualdades sociais na morfologia urbana das cidades brasileiras. Anais, do Simposio de cidades médias e 
pequenas da Bahia. Vitória da Conquista, Edições Uesb, 2011. Disponível em: http://periodicos.uesb.br/index.php/ascmpa/article/view/3653 acesso em setembro de 2017.

SANTOS, Jânio. .A natureza contraditória da Urbanização em um contexto de maiorcomplexidade na produção das cidades Baianas. In: LOPES, Diva Maria Ferlin;HENRIQUE, Wendel. (Orgs). Cidades Médias e Pequenas: teorias, conceitos e estudos de caso. Salvador: SEI, 2010.

Ações do estado e o papel das cidades médiasbaianas nos planos da urbanização capital. In: DIAS, Patrícia Chame; SANTOS, Jânio (Orgs.) Cidades médias e pequenas: contradições, mudanças e permanências nos espaços urbanos. Salvador: SEI, 2012.238 p.

SECCHI, Leonardo. Políticas públicas - conceitos, esquemas de análise, casos práticos - $2^{\mathrm{a}}$ Ed. 2013. São Paulo. Cengage Learning. 2013.

Recebido em: 22/10/2017

Aceito para publicação em: 30/11/2017 